\title{
Serial T1-weighted magnetic resonance imaging changes in a patient with central diabetes insipidus, possibly due to lymphocytic infundibuloneurohypophysitis
}

\author{
$\mathrm{T}$ Ikema and N Takasu \\ Department of Endocrinology and Metabolism, Department of Internal Medicine, University of the Ryukyus, Uehara 270, Nishihara, Okinawa, \\ Japan 902-0215 \\ (Correspondence should be addressed to N Takasu; Email: takasun@med.u-ryukyu.ac.jp)
}

Central diabetes insipidus (CDI), characterized by polydipsia and polyuria due to vasopressin deficiency, is familial, idiopathic or secondary. Idiopathic CDI, which accounts for $10 \%$ to $30 \%$ of cases of CDI (1), is characterized by selective hypofunction of the hypothalamic-neurohypophysial system. Idiopathic CDI could be an autoimmune disorder (2). Imura et al. (3) studied the processes of idiopathic CDI by magnetic resonance imaging (MRI), found abnormalities in the pituitary stalk and neurohypophysis, and performed biopsies that demonstrated lymphocytic inflammation. Their cases were diagnosed with CDI due to lymphocytic infundibuloneurohypophysitis. Their study provided new insight into the pathogenesis of CDI. However, they did not demonstrate the serial changes by MRI. We demonstrate the serial T1-weighted MRI changes in a 52-year-old woman with CDI possibly due to lymphocytic infundibuloneurohypophysitis. The initial MRI findings on admission were prominent pituitary-stalk thickening and neurohypophysial enlargement. These findings suggested that the patient had lymphocytic infundibuloneurohypophysitis $(3-5)$. The serial T1weighted MRI changes which occurred over the years were (i) prominent pituitary-stalk thickening and neurohypophysial enlargement, (ii) their improvement, and finally (iii) empty sella. The MRI changes are associated with the clinical course of the disease. Steroids were not administered to the patient; she recovered from CDI spontaneously. This is the first report to demonstrate the natural course of serial MRI changes in a patient with CDI possibly due to lymphocytic infundibuloneurohypophysitis.

A 52-year-old woman had been well until 27 October 2002, when she began to have extreme thirst and excessive urine output. She visited us on 2 December 2002. She had extreme thirst and had started to drink more than 2 liters water a day. She had decreased anti-diuretic hormone $(\mathrm{ADH})$ levels $(0.3 \mathrm{ng} / \mathrm{l}$, reference range $0.3-$ $3.5 \mathrm{ng} / \mathrm{l}$ ) with a low urine osmolality of $100 \mathrm{mOsm} / \mathrm{kg}$, high plasma osmolality of $310 \mathrm{mOsm} / \mathrm{kg}$ (reference range $278-305 \mathrm{mOsm} / \mathrm{kg}$ ), and a high serum sodium (Na) level (147 mmol/l). She was admitted on 8 December 2002. On admission, she was wellorientated (blood pressure: 110/65 $\mathrm{mmHg}$; heart rate: 70 beats/min). ADH levels were $0.5 \mathrm{ng} / \mathrm{l}$ and she had low urine osmolality $(98 \mathrm{mOsm} / \mathrm{kg})$ and high plasma osmolality (307 mOsm $/ \mathrm{kg})$. Her serum $\mathrm{Na}$ was $144 \mathrm{mmol} / \mathrm{l}$, and serum K was $4.2 \mathrm{mmol} / \mathrm{l}$. Her serum total triiodothyronine was $2.15 \mathrm{nmol} / \mathrm{l}$ (reference range 0.91-2.70 nmol/l), serum total thyroxine was $106 \mathrm{nmol} / \mathrm{l}$ (reference range $58-115 \mathrm{nmol} / \mathrm{l}$ ), and serum thyrotropin was $1.5 \mathrm{mU} / \mathrm{l}$ (reference range 0.3-4.0 mU/l). She had negative thyroglobulin-, thyroid peroxidase-, and pituitary-antibodies. Her morning plasma cortisol level was $405 \mathrm{nmol} / \mathrm{l}$ (reference range 160-810 nmol/l), and adrenocorticotropin was $7.15 \mathrm{pmol} / \mathrm{l}$ (reference range less than $13.2 \mathrm{pmol} / \mathrm{l}$ ).

The diagnosis of CDI was made on the basis of the decreased ADH levels with low urine osmolality and high plasma osmolality. T1-weighted MRI (Fig. 1A,D) revealed prominent pituitary-stalk thickening and neurohypophysial enlargement, indicating lymphocytic infundibuloneurohypophysitis that caused CDI. Her CDI was controlled with vasopressin. She was not treated with steroids. She recovered from CDI spontaneously and vasopressin was discontinued.

T1-weighted MRI (Fig. 1A,D) revealed prominent pituitary-stalk thickening and neurohypophysial enlargement. An MRI scan in March 2003 (Fig. 1B,E) demonstrated improvement of pituitary-stalk thickening and neurohypophysial enlargement. An MRI scan in June 2004 (Fig. 1C,F) revealed an empty sella. With improvement of pituitary-stalk thickening and neurohypophysial enlargement, she recovered from CDI. The serial MRI changes prominent pituitary-stalk thickening and neurohypophysial enlargement (A, D), their improvement $(\mathrm{B}, \mathrm{E})$, and then the empty sella $(\mathrm{C}, \mathrm{F})$, were associated with the clinical course of the disease. She was not treated with steroids. The serial MRI changes might show a natural course of lymphocytic infundibuloneurohypophysitis. 

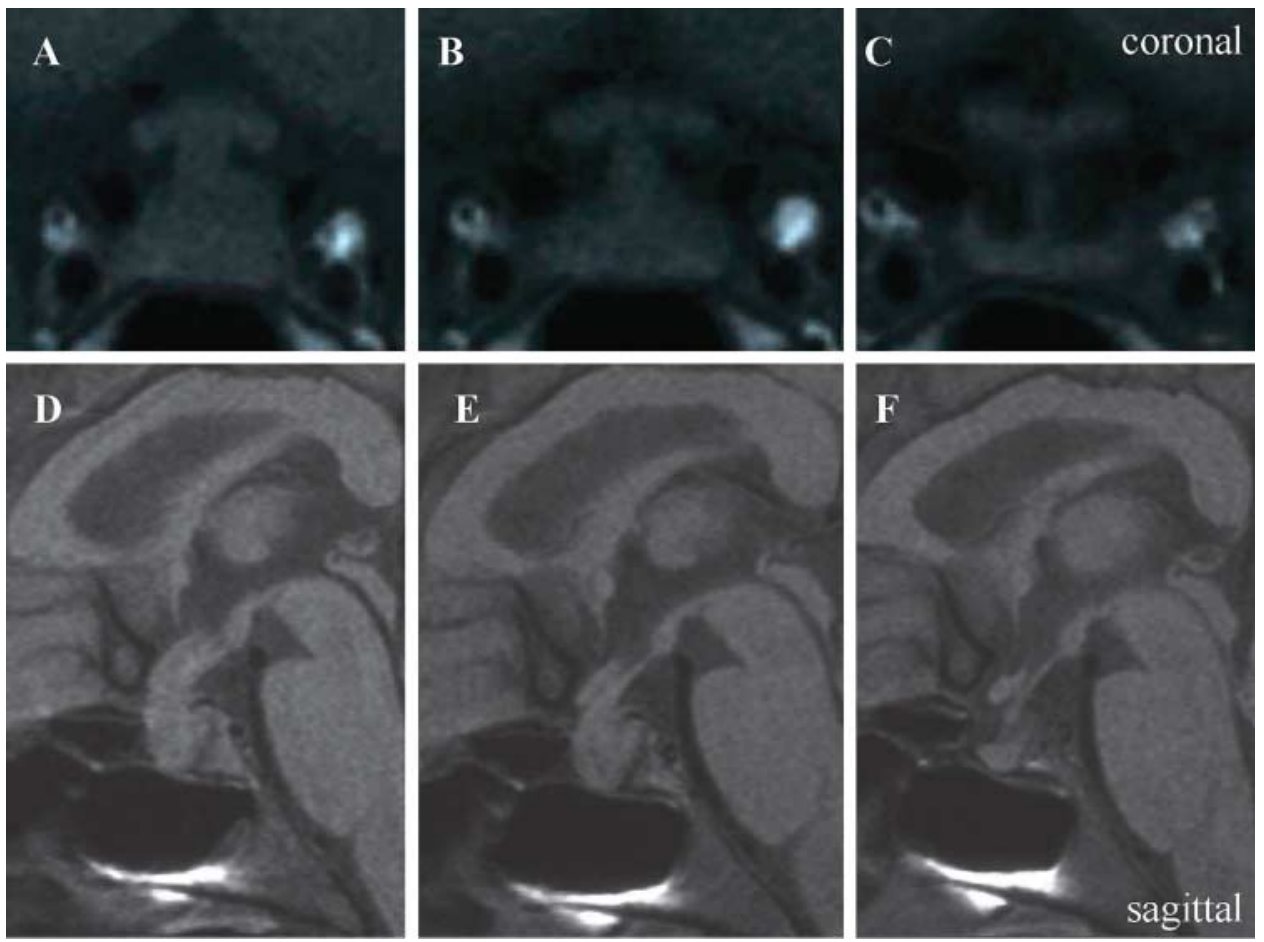

Figure 1 Serial T1-weighted magnetic resonance imaging (MRI) of a patient with central diabetes insipidus (CDI) possibly due to lymphocytic infundibuloneurohypophysitis. T1-weighted MRI in December 2002 (A, D) revealed prominent pituitary-stalk thickening and neurohypophysial enlargement, indicating lymphocytic infundibuloneurohypophysitis, which caused CDI. MRI in March 2003 (B, E) demonstrated improvement in the pituitary-stalk thickening and neurohypophysial enlargement. MRI in June 2004 (C, F) revealed empty sella. A, B, C: coronal view; D, E, F: sagittal view.

In our patient, the initial MRI findings were prominent pituitary-stalk thickening and neurohypophysial enlargement, suggesting that she had lymphocytic infundibuloneurohypophysitis (3-5). Lymphocytic infundibuloneurohypophysitis is typically observed in women during late pregnancy or in the postpartum period but may be seen at any age and in either gender. We demonstrated the serial MRI changes in a patient with CDI possibly due to lymphocytic infundibuloneurohypophysitis. The MRI changes are associated with the clinical course. Steroids were not administered to the patient and she recovered from CDI.

We demonstrated serial T1-weighted MRI changes in a patient with lymphocytic infundibuloneurohypophysitis. CDI can be caused by lymphocytic infundibuloneurohypophysitis, which can be detected by MRI. The clinical course of the disorder is associated with T1-weighted MRI changes.

\section{References}

1 Greger NG, Kirkland RT, Clayton GW \& Kirkland JL. Central diabetes insipidus: 22 years' experience. American Journal of Diseases of Children 1986140 551-554.

2 Scherbaum WA, Czernichow P, Bottazzo GF \& Doniach D. Diabetes insipidus in children. IV. A possible autoimmune type with vasopressin cell antibodies. Journal of Pediatrics 1985107 922-925.

3 Imura H, Nakao K, Shimatsu A, Ogawa Y, Sando T, Fujisawa I \& Yamabe H. Lymphocytic infundibuloneurohypophysitis as a cause of central diabetes insipidus. New England Journal of Medicine $1993329683-689$.

4 Leger J, Velasquez A, Garel C, Hassan M \& Czernichow P. Thickened pituitary stalk on magnetic resonance imaging in children with central diabetes insipidus. Journal of Clinical Endocrinology and Metabolism $1999 \mathbf{8 4}$ 1954-1960.

5 Cheung CC, Ezzat S, Smyth HS \& Asa SL. The spectrum and significance of primary hypophysitis. Journal of Clinical Endocrinology and Metabolism $2001 \mathbf{8 6} 1048-1053$.

Received 2 September 2005

Accepted 9 September 2005 